\title{
ON THE ERDŐS-LAX INEQUALITY CONCERNING POLYNOMIALS
}

\author{
Gradimir V. Milovanović AND ABDUllah Mir
}

Abstract. If $P(z)$ is a polynomial of degree $n$ which does not vanish in $|z|<k$, where $k \leqslant 1$, then N. K. Govil [On a theorem of S. Bernstein, Proc. Nat. Acad. Sci., 50 (1980), 50-52] proved that

$$
\max _{|z|=1}\left|P^{\prime}(z)\right| \leqslant \frac{n}{1+k^{n}} \max _{|z|=1}|P(z)|,
$$

provided $\left|P^{\prime}(z)\right|$ and $\left|Q^{\prime}(z)\right|$ attain maximum at the same point on $|z|=1$, where $Q(z)=$ $z^{n} \overline{P(1 / \bar{z})}$. In this paper, we obtain certain refinements and generalizations of this inequality and related results.

Mathematics subject classification (2010): 30A10, 30C10, 30D15.

Keywords and phrases: Polynomial, minimum modulus principle, Rouché's theorem, zeros.

\section{REFERENCES}

[1] A. AzIZ And N. Ahmad, Inequalities for the derivative of a polynomial, Proc. Indian Acad. Sci. Math. Sci., 107 (1997), 189-196.

[2] S. BERnSteIn, Sur l'ordre de la meilleure approximation des functions continues par des polynomes de degré donné, Mem. Acad. R. Belg., 4 (1912), 1-103.

[3] N. K. Govil, On a theorem of S. Bernstein, Proc. Nat.Acad. Sci., 50 (1980), 50-52.

[4] N. K. Govil AND Q. I. RAHMAn, Functions of exponential type not vanishing in a half plane and related polynomials, Trans. Amer. Math. Soc., 137 (1969), 501-517.

[5] N. K. GoviL, M. A. QAZI AND Q. I. RAHMAN, Inequalities describing the growth of polynomials not vanishing in a disk of prescribed radius, Math. Inequal. Appl., 6 (2003), 453-467.

[6] V. K. JAIn, On the derivative of a polynomial, Bull. Math. Soc. Sci. Math. Roumanie, 59 (2016), 339-347.

[7] P. D. LAX, Proof of a conjecture of P. Erdós on the derivative of a polynomial, Bull. Amer. Math. Soc., 50 (1944), 509-513.

[8] M. A. Malik, On the derivative of a polynomial, J. Lond. Math. Soc., 1 (1969), 57-60.

[9] M. Marden, Geometry of Polynomials, Math. Surveys, No. 3, Amer, Math. Soc., Providence, R.I., 1966.

[10] G. V. Milovanović, D. S. Mitrinović and Th. M. Rassias, Topics in Polynomials: Extremal Problems, Inequalities, Zeros, World Scientific Publishing Co., Singapore, 1994.

[11] Q. I. RAhman AND G. SchmeISSER, Analytic Theory of Polynomials, Oxford University Press Inc., New York, 2002. 